\title{
A Structural View on ESCRT-Mediated Abscission
}

\author{
Péter Horváth^ and Thomas Müller-Reichert* \\ Experimental Center, Faculty of Medicine Carl Gustav Carus, Technische Universität Dresden, Dresden, Germany
}

The endosomal sorting complex required for transport (ESCRT) mediates cellular processes that are related to membrane remodeling, such as multivesicular body (MVB) formation, viral budding and cytokinesis. Abscission is the final stage of cytokinesis that results in the physical separation of the newly formed two daughter cells. Although abscission has been investigated for decades, there are still fundamental open questions related to the spatio-temporal organization of the molecular machinery involved in this process. Reviewing knowledge obtained from in vitro as well as in vivo experiments, we give a brief overview on the role of ESCRT components in abscission mainly focussing on mammalian cells.

\section{OPEN ACCESS}

Edited by:

Maria Grazia Giansanti, Italian National Research Council, Italy

Reviewed by:

Pier Paolo D'Avino, University of Cambridge, United Kingdom John McCullough,

The University of Utah, United States

*Correspondence:

Thomas Müller-Reichert mueller-reichert@tu-dresden.de

Péter Horváth

peter.horvath@tu-dresden.de

Specialty section:

This article was submitted to Cell Growth and Division,

a section of the journal

Frontiers in Cell and Developmental

Biology

Received: 24 July 2020 Accepted: 16 October 2020 Published: 09 November 2020

Citation:

Horváth $P$ and Müller-Reichert T (2020) A Structural View on ESCRT-Mediated Abscission. Front. Cell Dev. Biol. 8:586880. doi: 10.3389/fcell.2020.586880
Keywords: endosomal sorting complexes required for transport (ESCRT), cytokinesis, abscission, microtubules, membranes, electron microscopy, electron tomography, 3D reconstruction

\section{INTRODUCTION}

Cytokinesis, the physical separation of newly formed daughter cells, is a very sophisticated process that is precisely coordinated and controlled by a complex molecular machinery. Proteome analysis revealed 577 proteins in purified intact midbodies of Chinese hamster ovary $(\mathrm{CHO})$ cells (Skop et al., 2004) and 1730 proteins in the midbody interactome of HeLa cells (Capalbo et al., 2019). In addition, the midbody remnant in HeLa cells consisted of 1732 proteins (Addi et al., 2020). To systematically analyze cytokinesis, it is practical to break this complex process into the following discrete steps: assembly and ingression of the contractile actin ring to achieve a primary constriction leading to the formation of the intercellular bridge; rearrangement of microtubules during bridge formation; and secondary constriction of the intercellular bridge culminating in abscission (Bhutta et al., 2014). There are distinct processes controlling the order of events in abscission of animal cells: formation, stabilization and severing of microtubules at the intercellular bridge and membrane constriction followed by a scission event as the closing step.

The endosomal sorting complex required for transport (ESCRT) machinery has been linked to the process of abscission (Carlton and Martin-Serrano, 2007; Morita et al., 2007; Carlton et al., 2008; Guizetti and Gerlich, 2010). In addition to cytokinesis (Glotzer, 2001; Eggert et al., 2006; Barr and Gruneberg, 2007), the ESCRTs are also involved in a variety of other processes, such as multivesicular body (MVB) biogenesis (Teis et al., 2008; Tang et al., 2016), viral budding (Garrus et al., 2001) and nuclear membrane reformation (Stoten and Carlton, 2018). The common aspect of all these processes is that they are all related to membrane remodeling. The core of the ESCRT machinery consists of ESCRT-0, ESCRT-I, ESCRT-II, and ESCRT-III complexes and vacuolar protein sorting-associated protein 4 (VPS4) (Olmos and Carlton, 2016; Christ et al., 2017; Zhu et al., 2017; Gatta and Carlton, 2019). In eukaryotes, ESCRT-III and VPS4 are involved in the late phases of cytokinesis (Adell and Teis, 2011; Vietri et al., 2015). This is in contrast to the role of ESCRT-I and ESCRT-II, which coordinate the assembly of downstream complexes necessary 
for cytokinesis (Schmidt and Teis, 2012). Reporting on the role of the ESCRT-III complex and associated protein components, we provide here an structural view on abscission focusing mainly on mammalian cells.

\section{FORMATION OF THE INTERCELLULAR BRIDGE}

The initiation of mitotic exit is based on cyclin-dependent kinase (CDK1), a universal protein kinase regulator. Cytokinesis is associated with down-regulation of CDK1 activity by phosphoregulation carried out by the coordinated action of kinases, counteracting phosphatases and association with cyclins (Hunt, 1991). Misregulation of CDK1 can prevent cytokinesis presumably because of its role in guiding and maintaining cleavage signals (Wheatley and Wang, 1996; Wheatley et al., 1997). Besides CDK1, Aurora B-dependent phosphorylation of the mitotic kinesin-like protein 1 (MKLP1) (Guse et al., 2005) is also essential for cytokinesis (Eggert et al., 2006). After furrow ingression both Aurora B and MKLP1 localize to the midbody, suggesting that the two proteins are involved subsequently in the regulation of abscission. Timing of abscission is regulated by Aurora B through phosphorylation of the human ESCRT-III subunit, charged multivesicular body protein 4C (CHMP4C) (Capalbo et al., 2012) in concert with VPS4 and abscission/NoCut checkpoint regulator (ANCHR) (Thoresen et al., 2014).

Concomitant with the rearrangement of the mitotic spindle into the central spindle, the actomyosin ring induces furrow ingression, thus leading to the formation of the intercellular bridge containing the midbody (Figure 1A). Actomyosindriven contraction of the cleavage furrow continues until the intercellular bridge with the midbody at its center has been formed (Mierzwa and Gerlich, 2014). The ingressed furrow then needs to be stabilized to prevent furrow regression. Centralspindlin was identified as a protein complex with plasma membrane tethering activity. The C1 domain of the centralspindlin subunit, male germ cell rac GTPase-activating protein (MgcRacGAP) associates with phosphoinositide lipids (Lekomtsev et al., 2012). This link is thought to have a stabilizing role to secure the final steps of cytokinesis in animal cells. An additional protein with a stabilizing function of the midspindle is protein regulator of cytokinesis 1 (PRC1) (Lee et al., 2015). Centralspindlin and PRC1 show microtubule binding activities. Both proteins co-localize to the midbody and recruit additional factors, such as Kruppel-like factor (KLF4) (Lee et al., 2015). PRC1 is required for midzone formation, and KLF4 is necessary for organization of the central spindle (Kurasawa et al., 2004). The contractile ring protein, anillin was also proposed to play a role in stabilizing the membrane invagination after myosin II-mediated force production ceases (Field and Alberts, 1995). Furthermore, anillin recruits septins, involved in the formation of the constriction sites (Renshaw et al., 2014). The C-terminus of anillin can bind septins, linking anillin and septins to membrane stabilization (Kinoshita et al., 2002; Menon and Gaestel, 2015; Karasmanis et al., 2019).

\section{MODELS OF ABSCISSION}

The physical separation of post-mitotic daughter cells is accompanied by a continuous decrease in the diameter of the intercellular bridge at the two opposing sides of the midbody. Initiated by furrow ingression, abscission is the net result of many complex and precisely orchestrated subprocesses (Agromayor and Martin-Serrano, 2013; Henne et al., 2013; Mierzwa and Gerlich, 2014; Frémont and Echard, 2018; Karasmanis et al., 2019). According to the vesicle-mediated model, midbody ringlocalized secretory vesicles fuse with each other and with the plasma membrane. Release of the vesicle content is thought to be mediated by synaptosomal-associated protein 23/25 (SNAP23/25) and vesicle-associated snap receptor (v-SNARE) (Takahashi et al., 2004). Thus, abscission is proposed to take place at the site of vesicle fusion (Gromley et al., 2005). The caveat is that vesicles were no longer detectable within the intercellular bridge by the time abscission occured (Guizetti et al., 2011). In contrast to the vesicle-mediated model, the mechanical force model suggests that traction based forces generated by adherent cells induce abscission. Based on a comparison to the Xenopus oocyte, this model suggests a "wound-induced closure" mechanism at late cytokinesis (Darenfed and Mandato, 2005; Schiel and Prekeris, 2010).

In the following sections, we will focus on the role of ESCRT proteins and their spatial distribution in cell division. ESCRTIII components are primary candidates for the completion of cytokinesis (Wollert et al., 2009). Secondary constriction sites develop either at both sides of the midbody or in some cases only at one side (Mullins and Biesele, 1977; Schiel et al., 2012). In search of interacting partners of ESCRT-III, it was found that tumor susceptibility gene 101 protein (TSG101), a subunit of ESCRT-I, binds the centrosomal protein of $55 \mathrm{kDa}$ (CEP55) (Fabbro et al., 2005) and the apoptosis-linked gene 2-interacting protein x (ALIX) (Morita et al., 2007; Carlton et al., 2008). In fact, CEP55 recruits TSG101 and ALIX to the midbody (Lee et al., 2008). Depletion of ALIX by RNA interference resulted in a 14fold increase in multinucleated cells compared to control cells, suggesting a role for ALIX in cytokinesis (Carlton and MartinSerrano, 2007). ALIX acts as an adaptor molecule connecting CEP55 with ESCRT-III to initiate completion of cytokinesis (Carlton et al., 2008). The CHMP4 subunits of ESCRT-III localize next to the midbody and polymerize toward the direction of the constriction site (Guizetti et al., 2011). In support of this observation, membrane deforming and interaction properties of ESCRT-III components were documented (Darenfed and Mandato, 2005; Hanson et al., 2008; Malerød and Stenmark, 2009). Based on studies of syndecan-syntenin-ALIX interaction in the case of exosome formation (Baietti et al., 2012), a recent study suggested a two-phase recruitment of ESCRT-III, involving a tripartite module (ALIX-syntenin-syndecan-4) to be essential for localization and abscission. ALIX-syntenin anchors ESCRTIII to the membrane, while syndecan-4 stabilizes ESCRT-III polymers at the abscission site (Addi et al., 2020).

Importantly, ESCRT-III-mediated secondary constriction requires synchronization with the disassembly of microtubules within the intercellular bridge. Increased concentration of the 

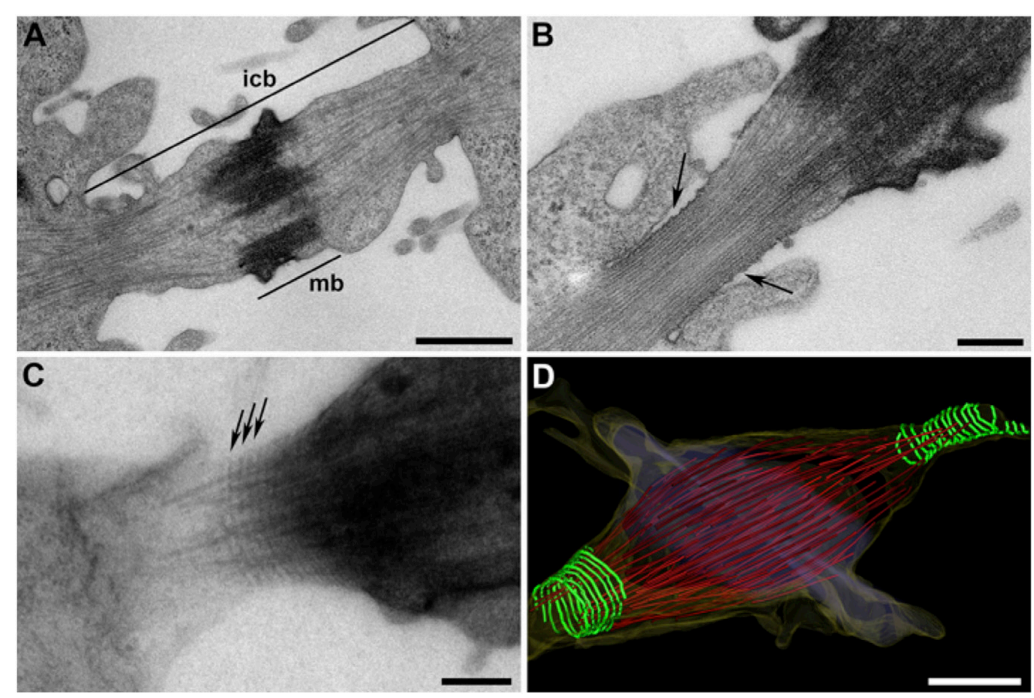

FIGURE 1 | Ultrastructure of the abscission machinery in HeLa cells. (A) Thin-section electron micrograph of a chemically fixed intercellular bridge (icb). This overview image also shows the midbody (mb). (B) Visualization of a secondary constriction site. Image of a chemically fixed intercellular bridge showing a typical "ruffled zone" with membrane thickening (arrows). (C) Semi-thick serial section of a high-pressure frozen, freeze substituted and plastic-embedded sample as visualized by electron tomography. Filamentous structures (arrows) oriented perpendicular to the long axis of the bridge are shown. (D) 3D model of an intercellular bridge revealed by serial-section electron tomography. 3D rendering of ESCRT-III-dependent filaments (green), microtubules (red) and the cell membrane (yellow). The filaments show different degrees of constriction as previously reported (Guizetti et al., 2011). Scale bars (A,D), $1 \mu \mathrm{m}$; (B,C), $250 \mathrm{~nm}$.

microtubule-severing enzyme, spastin can be measured at the site where microtubule disassembly takes place (Yang et al., 2008; Connell et al., 2009; Guizetti et al., 2011). How the components of the ESCRT-III machinery are orchestrated during abscission in vivo remains largely elusive. One possibility is that plasma membrane-attached ESCRT-III filaments increase their curvature as they extend from the midbody, constricting the membrane until scission takes place (Guizetti et al., 2011). Another possibility involves an increase in constriction by remodeling ESCRT-III subunits by Vps4 (Mierzwa et al., 2017). It has also been proposed that filaments may slide along the intercellular bridge and exert constriction determined by the elastic forces in the membrane (Elia et al., 2012).

\section{STRUCTURAL STUDIES ON ISOLATED ESCRT COMPONENTS}

The ESCRT machinery is conserved from archaea to humans (Hurley and Emr, 2006; Lindås et al., 2008; Schöneberg et al., 2017; Gupta et al., 2020). The 12 human homologs of ESCRT-III and VPS4 were shown to contribute to cytokinesis (Carlton and Martin-Serrano, 2007; Morita et al., 2007; Caballe and MartinSerrano, 2011; Schöneberg et al., 2017). The ESCRT-III proteins show structural variance, but the four $\mathrm{N}$-terminal helices are homologous. The C-terminal truncated CHMP38-183 crystal structure with a truncated C-terminal acidic domain (Muzioł et al., 2006) served as a search model for molecular replacement of CHMP38-222 (Bajorek et al., 2009).

Depending on the composition of the lipid monolayer and the interacting ESCRT-III subunits, self-assembled ESCRT-III heteropolymers can adopt structures of variable dynamics and architectures such as rings, spirals, helices or linear polymers (Hanson et al., 2008; Henne et al., 2012). As an example, yeast vacuolar-sorting protein ( $\mathrm{Snf}^{\mathrm{CHMP}}{ }^{\mathrm{A} ; \mathrm{B} ; \mathrm{C}}$ ), a core component of ESCRT-III polymerizes into spirals at the surface of lipid bilayers, mediating membrane deformation and fission (Chiaruttini et al., 2015). In addition the ESCRT-III subunits isolated from yeast, Vps2 ${ }^{\text {CHMP2A,B }}$, Vps $20^{\text {CHMP6 }}$, Vps2 $24^{\text {CHMP3 }}$, and also Snf7 were proposed to form filaments and deform membranes (Cashikar et al., 2014). Although Snf7 by itself is unable to induce buckling on artificial lipid membranes, Vps2/Vps24 drive the formation of spirals (Henne et al., 2012) and form a parallel strand through electrostatic interaction with Snf7 (Mierzwa et al., 2017; Mandal et al., 2020). Incubation of Snf7/Vps2/Vps24 with detergent-solubilized lipids resulted in helices of different forms (Moser von Filseck et al., 2020).

A recent cryo-electron microscopy (cryo-EM) study at $3.2 \AA$ resolution showed a double-stranded helical arrangement of Vps24. Lipids were shown to assist in the disassembly of the filaments. This study further revealed the following three important aspects of Vps24 function: First, apolar Vps24 integrates into linear polar Snf7 polymers, thereby neutralizing the polarity so that opposite polarity filaments can combine (Huber et al., 2020). Second, it was shown that Vps24 has an intrinsical helical property. Under defined conditions, Vps24 is capable of inducing curvature in flat Snf7 polymers (Henne et al., 2012; Tang et al., 2015). Third, Vps24 consists of two protofilaments. Based on a lateral association of Vps2/Vps24 and Snf7, this could allow a combination of multiple linear Snf7 filaments (Mierzwa et al., 2017; Huber et al., 2020). All this suggested that Vps24 is a candidate for 
an adaptor complex that connects ESCRT-III homopolymers (Huber et al., 2020).

In a study of ESCRT-III-driven shaping of positively curved membranes, the membrane-bound complex CHMP1B-IST1 was shown to constrict the underlying membrane bilayer nearly to the fission point by a two-component sequential polymerization mechanism (Nguyen et al., 2020). Spontaneous co-assembly between CHMP1 and truncated IST1 frequently resulted in conical helix shapes with decreasing diameter under low ionic strength, whereas an increasing ionic strength favored the monomeric form of the subunits (McCullough et al., 2015). The other way round, membrane shape was also reported to influence the assembly of ESCRT-III subunits. In contrast to in vivo conditions, in vitro experiments showed that CHMP2B and CHMP2A/CHMP3 assemble on positively curved but not on negatively curved membranes. This suggests that these complexes don't assemble inside membrane structures (negative curvature) but rather on the outside surface (positive curvature). Moreover, CHMP4B has a preference to bind either to flat membranes or to tubes with positive mean curvature (Bertin et al., 2020). Last but not least, it is important to note that polymeric structures can also form even in the absence of membranes (Henne et al., 2012; Banjade et al., 2019). Therefore, it will be crucial in future studies to verify the reported molecular shapes and membrane interactions of the various ESCRT-III components within the cellular context of abscission.

\section{ROLE OF VPS4 IN REGULATING ESCRT-III}

Vps4 is a member of the meiotic clade AAA-ATPase and a key component of the ESCRT pathway (Monroe and Hill, 2016). Its $\mathrm{N}$-terminus consists of a microtubule interacting and trafficking (MIT) domain, which interacts with carboxy-terminal peptide, MIT interaction motifs (MIM) in ESCRT-III proteins (Obita et al., 2007; Stuchell-Brereton et al., 2007; Kieffer et al., 2008). This is followed by a linker region (Shestakova et al., 2013) and an AAA-ATPase cassette that consists of a large ATPase and a small ATPase domain, a beta domain and a C-terminal helix (Scott et al., 2005; Gonciarz et al., 2008). Vps4 also binds the activator vacuolar protein sorting-associated protein (Vta1) (Yeo et al., 2003; Shestakova et al., 2010), which contacts the beta domain and regulates assembly of Vps4 and ATPase activity (Azmi et al., 2006). In the cytosol, Vps4 is present mainly as a monomer but it forms hexamers in its activated form (Monroe et al., 2014; Adell et al., 2017). The hexamers are associated to each ESCRT-III filament by the MIT-MIM interaction. The cryoEM structure at $4.3 \AA$ resolution revealed that Vps4 is highly asymmetric and stabilized by ATP and Vta1 binding. One end of the Vps4 molecule grows and hydrolyzes ATP, while the other end disassembles (Monroe et al., 2017). The disassembled subunits were reported to move to the growing site, creating a "walking" motion of Vps4 along the ESCRT-III filament, pulling it through the pore of the hexamer and therefore disassembling the filament (Yang et al., 2015; Adell et al., 2017; Monroe et al., 2017).

While regulating assembly and disassembly of ESCRTIII complexes, Vps4 can also promote shape adaptations to membranes with different curvatures (Mierzwa et al., 2017), allowing Vps4 to function in a wide range of processes. Highspeed atomic force microscopy (HS-AFM) imaging of Vps4 with Vps2, Vps24, and Snf7 on lipid bilayers showed ESCRTIII spirals with reduced diameter in the presence of ATP. From this observation it was concluded that Vps4 is responsible for a dynamic subunit turnover and that Vps2, Vps24 subunits function as inhibitors (Mierzwa et al., 2017). Vps24 induced curvature when mixed with flat Snf7 filament polymers (Henne et al., 2012; Tang et al., 2015). Vps2/Vps24 subunits of ESCRTIII formed side by side filaments with Snf7 (Mierzwa et al., 2017). Furthermore, Vps2/Vps24 is crucial for Vps4-mediated remodeling. Polymerized Snf7 on membranes mixed with Vps4 and ATP didn't induce remodeling of the Snf7 filaments. However, the combination of Snf7, Vps2/Vps24, Vps4, and ATP resulted in both shrinking and growth of ESCRT-III spirals (Mierzwa et al., 2017). This dynamic remodeling of ESCRT-III argues against the previously proposed "cut and slide" model, which suggested a single cut by VPS4 to trigger constriction (Elia et al., 2012).

\section{STRUCTURAL APPROACHES TO STUDY THE FUNCTION OF ESCRTS IN VIVO}

Structural analysis of cytokinesis is challenging given that the spatial organization of the abscission machinery is complex and the interactions of the different components are dynamic and possibly transient. In order to reduce the complexity, cytokinesis has been studied predominantly under in vitro conditions. This approach allows the assessment of the roles of specific components of the machinery by taking them out of the physiological context and placing them into a defined artificial environment. As a result of the "resolution revolution", cryo-EM is now the method of choice for the determination of 3D structures of large macromolecular assemblies in vitro at near atomic resolution (Callaway, 2020). Ultimately, however, cytokinesis should also be studied within the cellular context.

The first in vivo study on cytokinesis used fixed HeLa cells and revealed an elongated intercellular bridge (Byers and Abramson, 1968). The elongated bridge showed membrane thickenings, called "waves." These waves were claimed to relate to translational forces acting along arrays of microtubules. Concerted waves passing from the midbody to the cell were thought to exert forces on the connected cells, resulting in a separation of the cell pair (Byers and Abramson, 1968). Using D-98S cells, it was possible to quantify the change in the diameter of the intercellular bridge over time. The reduction in diameter was attributed to two subprocesses (Mullins and Biesele, 1977): first, a systematic breakdown of the midbody structure, and second a constriction causing a disintegration and a spatial rearrangement of microtubules. Along the narrowed plasma membrane of cellular bridges, wave-like ripples on both sides adjacent to the midbody were also observed in this experiment analyzing chemically fixed cells (see also Figure 1B for an example in HeLa cells). However, there was no evident subcellular structure visible by thin-section electron microscopy causing these ripples. Stretching of the intercellular bridge was 
hypothesized to cause the final cut by reaching a "point of breakage" (Mullins and Biesele, 1977).

Membrane ripples were later observed by serial-section electron tomography of high-pressure frozen and freeze substituted intercellular bridges in HeLa cells (Guizetti et al., 2011). This study revealed intertwined helical filaments causing cortical constriction. The visualized filaments at the secondary constriction sites were $17.3 \pm 2.5 \mathrm{~nm}$ wide and showed a helical pitch of $35.3 \pm 4.1 \mathrm{~nm}$ (Figures 1C,D). Based on the helical properties of filaments assembled in vitro (Ghazi-Tabatabai et al., 2008; Hanson et al., 2008; Lata et al., 2008) and by comparison of wild-type and CHMP2A-depleted HeLa cells (Hanson et al., 2008; Guizetti et al., 2011), it was suggested that the in vivo observed filaments are polymerized ESCRT-III core components (Guizetti et al., 2011). However, a direct labeling of these ESCRTIII-dependent filaments, for instance by immuno-EM, has not been reported so far.

In terms of labeling, the antibody-stained ESCRT-IIIsubunit IST1 was visualized by stochastic optical reconstruction microscopy (STORM). It was shown that rings emanate parallel to the dark zone of the midbody. In later stages of abscission, spirals of IST1 were extending toward the abscission site with decreasing diameter and width (Goliand et al., 2018). Structural analysis of Madin-Darby canine kidney cells (MDCK) by soft X-ray cryo-tomography (Sherman et al., 2016) confirmed previous results regarding the membrane bulging from the midbody (Elia et al., 2011; Guizetti et al., 2011; Schiel et al., 2011; Crowell et al., 2014) and also showed membrane extrusions from the vicinity of the pre-abscission site. Three cortical rings were visualized with an average diameter of $1.43 \pm 0.25 \mu \mathrm{m}$. Furthermore, three intertwined helices were imaged with an average diameter of $556 \pm 15 \mathrm{~nm}$, one of the helices extended to the abscission site (Sherman et al., 2016).

\section{OUTLOOK}

A number of in vitro ultrastructural studies of ESCRT-III components are based on single-particle analyses by cryo-EM (Su et al., 2017; Maity et al., 2019; Bertin et al., 2020; Huber et al., 2020; Moser von Filseck et al., 2020; Nguyen et al., 2020; Pfitzner et al., 2020). While in vitro experiments provide useful structural information about the building blocks of the abscission machinery under artificial conditions, it is difficult to correlate this information with the dynamic attributes of the cytokinetic apparatus under physiological conditions. In addition, isolated components may form artificial structures, thus leading to molecular mechanisms that may not fully represent the molecular processes as observed within cells. Along this line, in vitro purification can cause aggregation of ESCRT-III proteins (Wollert et al., 2009), induce dramatic conformational changes, diverse morphologies (Schöneberg et al., 2017) and non-physiological interactions of interdependent subunits. Furthermore, another problematic issue of in vitro studies is the lack of biomimetic substrates that capture the in vivo conditions on which ESCRT-III components can act upon. For all these reasons, an in vitro reconstruction of the abscission machinery might therefore be insufficient to explain the complexity of abscission within cells. Moreover, cellular crowding and local concentrations of the ESCRT-III components may have significant effects on the mechanism of abscission, inasmuch as time-dependent aspects need to be considered when analyzing the cytokinetic apparatus.

Interestingly, the number of in vivo ultrastructural analyses on cytokinesis is currently very small (Elia et al., 2011; Guizetti et al., 2011; Sherman et al., 2016; Mierzwa et al., 2017; Goliand et al., 2018). In fact, a systematic time-resolved study on the ultrastructure of abscission has never been performed. In addition, models on ESCRT-III function deduced from in vitro experiments need to be benchmarked against cellular conditions. Certainly, more in vivo structural studies would result in a better understanding of the abscission machinery in cells and clarify some fundamental questions such as: How does the geometry of ESCRT-III change during the elongation of the intercellular bridge? What are the interacting partners of ESCRT-III? How do they interact and coordinate with each other during cytokinesis? How do other cytoskeletal components cooperate with ESCRT-III proteins and how does RNAi silencing of helix forming subunits affect the ultrastructure of the abscission machinery? Moreover, how are the $17-\mathrm{nm}$ cortical filaments anchored to the plasma membrane? To answer these questions, additional 3D analyses of intercellular bridges at defined time points need to be performed. Such time-resolved 4D studies will give important information on the development of the abscission machinery and the process of constriction.

In summary, while many high-resolution structures of subunits involved in abscission were solved under in vitro conditions, very little is known about the spatial organization and function of these subunits inside the cell. Therefore, in vivo ultrastructural studies should play an essential role in uncovering the discrete time-dependent steps of late cytokinesis. Subsequently, high-resolution structures should then be fitted into the electron density map of the abscission machinery. Thus, both in vitro and in vivo studies should be performed in parallel to grasp the full complexity of abscission across different imaging scales.

\section{AUTHOR CONTRIBUTIONS}

All authors listed have made a substantial, direct and intellectual contribution to the work, and approved it for publication.

\section{FUNDING}

TM-R received funding from the German Research Foundation (DFG grant MU 1423/12-1).

\section{ACKNOWLEDGMENTS}

The authors are grateful to Dr. Beata Mierzwa (UCSD), Dr. Julia Mahamid (EMBL Heidelberg), and Dr. Erin Tranfield (Instituto Gulbenkian de Ciencia) for a critical reading of the manuscript. 


\section{REFERENCES}

Addi, C., Presle, A., Frémont, S., Cuvelier, F., Rocancourt, M., Milin, F., et al. (2020). The Flemmingsome reveals an ESCRT-to-membrane coupling via ALIX/syntenin/syndecan-4 required for completion of cytokinesis. Nat. Commun. 11:1941. doi: 10.1038/s41467-020-15205-z

Adell, M. A., and Teis, D. (2011). Assembly and disassembly of the ESCRT-III membrane scission complex. FEBS Lett. 585, 3191-3196. doi: 10.1016/j.febslet. 2011.09.001

Adell, M. A. Y., Migliano, S. M., Upadhyayula, S., Bykov, Y. S., Sprenger, S., Pakdel, M., et al. (2017). Recruitment dynamics of ESCRT-III and Vps4 to endosomes and implications for reverse membrane budding. eLife 6:e31652. doi: 10.7554/eLife.31652

Agromayor, M., and Martin-Serrano, J. (2013). Knowing when to cut and run: mechanisms that control cytokinetic abscission. Trends Cell Biol. 23, 433-441. doi: $10.1016 /$ j.tcb.2013.04.006

Azmi, I., Davies, B., Dimaano, C., Payne, J., Eckert, D., Babst, M., et al. (2006). Recycling of ESCRTs by the AAA-ATPase Vps4 is regulated by a conserved VSL region in Vta1. J. Cell Biol. 172, 705-717. doi: 10.1083/jcb.200508166

Baietti, M. F., Zhang, Z., Mortier, E., Melchior, A., Degeest, G., Geeraerts, A., et al. (2012). Syndecan-syntenin-ALIX regulates the biogenesis of exosomes. Nat. Cell Biol. 14, 677-685. doi: 10.1038/ncb2502

Bajorek, M., Schubert, H. L., McCullough, J., Langelier, C., Eckert, D. M., Stubblefield, W. M., et al. (2009). Structural basis for ESCRT-III protein autoinhibition. Nat. Struct. Mol. Biol. 16, 754-762. doi: 10.1038/nsmb.1621

Banjade, S., Tang, S., Shah, Y. H., and Emr, S. D. (2019). Electrostatic lateral interactions drive ESCRT-III heteropolymer assembly. eLife 8:e46207. doi: 10. 7554/eLife.46207

Barr, F. A., and Gruneberg, U. (2007). Cytokinesis: placing and making the final cut. Cell 131, 847-860. doi: 10.1016/j.cell.2007.11.011

Bertin, A., de Franceschi, N., de la Mora, E., Maity, S., Alqabandi, M., Miguet, N., et al. (2020). Human ESCRT-III polymers assemble on positively curved membranes and induce helical membrane tube formation. Nat. Commun. 11:2663. doi: 10.1038/s41467-020-16368-5

Bhutta, M. S., McInerny, C. J., and Gould, G. W. (2014). ESCRT function in cytokinesis: location, dynamics and regulation by mitotic kinases. Int. J. Mol. Sci. 15, 21723-21739. doi: 10.3390/ijms151221723

Byers, B., and Abramson, D. H. (1968). Cytokinesis in HeLa: post-telophase delay and microtubule-associated motility. Protoplasma 66, 413-435. doi: 10.1007/ BF01255868

Caballe, A., and Martin-Serrano, J. (2011). ESCRT machinery and cytokinesis: the road to daughter cell separation. (2011). Traffic 12, 1318-1326. doi: 10.1111/j. 1600-0854.2011.01244.x

Callaway, E. (2020). 'It opens up a whole new universe': revolutionary microscopy technique sees individual atoms for first time. Nature 582, 156-157. doi: 10. 1038/d41586-020-01658-1

Capalbo, L., Bassi, Z. I., Geymonat, M., Todesca, S., Copoiu, L., Enright, A. J., et al. (2019). The midbody interactome reveals unexpected roles for PP1 phosphatases in cytokinesis. Nat. Commun. 10:4513. doi: 10.1038/s41467-01912507-9

Capalbo, L., Montembault, E., Takeda, T., Bassi, Z. I., Glover, D. M., and D’Avino, P. P. (2012). The chromosomal passenger complex controls the function of endosomal sorting complex required for transport-III Snf7 proteins during cytokinesis. Open Biol. 2:120070. doi: 10.1098/rsob.120070

Carlton, J. G., Agromayor, M., and Martin-Serrano, J. (2008). Differential requirements for Alix and ESCRT-III in cytokinesis and HIV-1 release. Proc. Natl. Acad. Sci. U.S.A. 105, 10541-10546. doi: 10.1073/pnas.0802008105

Carlton, J. G., and Martin-Serrano, J. (2007). Parallels between cytokinesis and retroviral budding: a role for the ESCRT machinery. Science 316, 1908-1912. doi: 10.1126/science.1143422

Cashikar, A. G., Shim, S., Roth, R., Maldazys, M. R., Heuser, J. E., and Hanson, P. I. (2014). Structure of cellular ESCRT-III spirals and their relationship to HIV budding. eLife 3:e02184. doi: 10.7554/eLife.02184

Chiaruttini, N., Redondo-Morata, L., Colom, A., Humbert, F., Lenz, M., Scheuring, S., et al. (2015). Relaxation of loaded ESCRT-III spiral springs drives membrane deformation. Cell 163, 866-879. doi: 10.1016/j.cell.2015.10.017

Christ, L., Raiborg, C., Wenzel, E. M., Campsteijn, C., and Stenmark, H. (2017). Cellular functions and molecular mechanisms of the ESCRT membrane-scission machinery. Trends Biochem. Sci. 42, 42-56. doi: 10.1016/ j.tibs.2016.08.016

Connell, J. W., Lindon, C., Luzio, J. P., and Reid, E. (2009). Spastin couples microtubule severing to membrane traffic in completion of cytokinesis and secretion. Traffic 10, 42-56. doi: 10.1111/j.1600-0854.2008.00847.x

Crowell, E. F., Gaffuri, A. L., Gayraud-Morel, B., Tajbakhsh, S., and Echard, A. (2014). Engulfment of the midbody remnant after cytokinesis in mammalian cells. J. Cell Sci. 127, 3840-3851. doi: 10.1242/jcs.154732

Darenfed, H., and Mandato, C. A. (2005). Wound-induced contractile ring: a model for cytokinesis. Biochem. Cell Biol. 83, 711-720. doi: 10.1139/o05-164

Eggert, U. S., Mitchison, T. J., and Field, C. M. (2006). Animal cytokinesis: from parts list to mechanisms. Annu. Rev. Biochem. 75, 543-566. doi: 10.1146/ annurev.biochem.74.082803.133425

Elia, N., Fabrikant, G., Kozlov, M. M., and Lippincott-Schwartz, J. (2012). Computational model of cytokinetic abscission driven by ESCRTIII polymerization and remodeling. Biophys. J. 102, 2309-2320. doi: 10.1016/j.bpj.2012.04.007

Elia, N., Sougrat, R., Spurlin, T. A., Hurley, J. H., and Lippincott-Schwartz, J. (2011). Dynamics of endosomal sorting complex required for transport (ESCRT) machinery during cytokinesis and its role in abscission. Proc. Natl. Acad. Sci. U.S.A. 108, 4846-4851. doi: 10.1073/pnas.1102714108

Fabbro, M., Zhou, B. B., Takahashi, M., Sarcevic, B., Lal, P., Graham, M. E., et al. (2005). Cdk1/Erk2- and Plk1-dependent phosphorylation of a centrosome protein, Cep55, is required for its recruitment to midbody and cytokinesis. Dev. Cell 9, 477-488. doi: 10.1016/j.devcel.2005.09.003

Field, C. M., and Alberts, B. M. (1995). Anillin, a contractile ring protein that cycles from the nucleus to the cell cortex. J. Cell Biol. 131, 165-178. doi: 10.1083/jcb. 131.1.165

Frémont, S., and Echard, A. (2018). Membrane traffic in the late steps of cytokinesis. Curr. Biol. 28, R458-R470. doi: 10.1016/j.cub.2018.01.019

Garrus, J. E., von Schwedler, U. K., Pornillos, O. W., Morham, S. G., Zavitz, K. H., Wang, H. E., et al. (2001). Tsg101 and the vacuolar protein sorting pathway are essential for HIV-1 budding. Cell 107, 55-65. doi: 10.1016/s0092-8674(01) 00506-2

Gatta, A. T., and Carlton, J. G. (2019). The ESCRT-machinery: closing holes and expanding roles. Curr. Opin. Cell Biol. 59, 121-132. doi: 10.1016/j.ceb.2019. 04.005

Ghazi-Tabatabai, S., Saksena, S., Short, J. M., Pobbati, A. V., Veprintsev, D. B., Crowther, R. A., et al. (2008). Structure and disassembly of filaments formed by the ESCRT-III subunit Vps24. Structure 16, 1345-1356. doi: 10.1016/j.str. 2008.06.010

Glotzer, M. (2001). Animal cell cytokinesis. Annu. Rev. Cell Dev. Biol. 17, 351-386. doi: 10.1146/annurev.cellbio.17.1.351

Goliand, I., Adar-Levor, S., Segal, I., Nachmias, D., Dadosh, T., Kozlov, M. M., et al. (2018). Resolving ESCRT-III spirals at the intercellular bridge of dividing cells using 3D STORM. Cell Rep. 24, 1756-1764. doi: 10.1016/j.celrep.2018. 07.051

Gonciarz, M. D., Whitby, F. G., Eckert, D. M., Kieffer, C., Heroux, A., Sundquist, W. I., et al. (2008). Biochemical and structural studies of yeast Vps4 oligomerization. J. Mol. Biol. 384, 878-895. doi: 10.1016/j.jmb.2008.09.066

Gromley, A., Yeaman, C., Rosa, J., Redick, S., Chen, C. T., Mirabelle, S., et al. (2005). Centriolin anchoring of exocyst and SNARE complexes at the midbody is required for secretory-vesicle-mediated abscission. Cell 123, 75-87. doi: 10. 1016/j.cell.2005.07.027

Guizetti, J., and Gerlich, D. W. (2010). Cytokinetic abscission in animal cells. Semin. Cell Dev. Biol. 21, 909-916. doi: 10.1016/j.semcdb.2010.08.001

Guizetti, J., Schermelleh, L., Mäntler, J., Maar, S., Poser, I., Leonhardt, H., et al. (2011). Cortical constriction during abscission involves helices of ESCRT-IIIdependent filaments. Science 331, 1616-1620. doi: 10.1126/science.1201847

Gupta, T. K., Klumpe, S., Gries, K., Heinz, S., Wietrzynski, W., and Ohnishi, N. (2020). Structural basis for VIPP1 oligomerization and maintenance of thylakoid membrane integrity. bioRxiv doi: 10.1101/2020.08.11.243204

Guse, A., Mishima, M., and Glotzer, M. (2005). Phosphorylation of ZEN-4/MKLP1 by aurora B regulates completion of cytokinesis. Curr. Biol. 15, 778-786. doi: 10.1016/j.cub.2005.03.041

Hanson, P. I., Roth, R., Lin, Y., and Heuser, J. E. (2008). Plasma membrane deformation by circular arrays of ESCRT-III protein filaments. J. Cell Biol. 180, 389-402. doi: 10.1083/jcb.200707031 
Henne, W. M., Buchkovich, N. J., Zhao, Y., and Emr, S. D. (2012). The endosomal sorting complex ESCRT-II mediates the assembly and architecture of ESCRT-III helices. Cell 151, 356-371. doi: 10.1016/j.cell.2012.08.039

Henne, W. M., Stenmark, H., and Emr, S. D. (2013). Molecular mechanisms of the membrane sculpting ESCRT pathway. Cold Spring Harb. Perspect. Biol. 5:a016766. doi: 10.1101/cshperspect.a016766

Huber, S. T., Mostafavi, S., Mortensen, S. A., and Sachse, C. (2020). Structure and assembly of ESCRT-III helical Vps24 filaments. Sci. Adv. 6:eaba4897. doi: 10.1126/sciadv.aba4897

Hunt, T. (1991). Cell biology. Destruction's our delight. Nature 349, 100-101. doi: 10.1038/349100a0

Hurley, J. H., and Emr, S. D. (2006). The ESCRT complexes: structure and mechanism of a membrane-trafficking network. Annu. Rev. Biophys. Biomol. Struct. 35, 277-298. doi: 10.1146/annurev.biophys.35.040405.102126

Karasmanis, E. P., Hwang, D., Nakos, K., Bowen, J. R., Angelis, D., and Spiliotis, E. T. (2019). A septin double ring controls the spatiotemporal organization of the ESCRT machinery in cytokinetic abscission. Curr. Biol. 29, 2174.e7-2182.e7. doi: 10.1016/j.cub.2019.05.050

Kieffer, C., Skalicky, J. J., Morita, E., De Domenico, I., Ward, D. M., Kaplan, J., et al. (2008). Two distinct modes of ESCRT-III recognition are required for VPS4 functions in lysosomal protein targeting and HIV-1 budding. Dev. Cell 15, 62-73. doi: 10.1016/j.devcel.2008.05.014

Kinoshita, M., Field, C. M., Coughlin, M. L., Straight, A. F., and Mitchison, T. J. (2002). Self- and actin-templated assembly of Mammalian septins. Dev. Cell 3, 791-802. doi: 10.1016/s1534-5807(02)00366-0

Kurasawa, Y., Earnshaw, W. C., Mochizuki, Y., Dohmae, N., and Todokoro, K. (2004). Essential roles of KIF4 and its binding partner PRC1 in organized central spindle midzone formation. Embo J. 23, 3237-3248. doi: 10.1038/sj. emboj.7600347

Lata, S., Schoehn, G., Jain, A., Pires, R., Piehler, J., Gottlinger, H. G., et al. (2008). Helical structures of ESCRT-III are disassembled by VPS4. Science 321, 1354-1357. doi: 10.1126/science.1161070

Lee, H. H., Elia, N., Ghirlando, R., Lippincott-Schwartz, J., and Hurley, J. H. (2008). Midbody targeting of the ESCRT machinery by a noncanonical coiled coil in CEP55. Science 322, 576-580. doi: 10.1126/science. 1162042

Lee, K. Y., Esmaeili, B., Zealley, B., and Mishima, M. (2015). Direct interaction between centralspindlin and PRC1 reinforces mechanical resilience of the central spindle. Nat. Commun. 6:7290. doi: 10.1038/ncomms8290

Lekomtsev, S., Su, K. C., Pye, V. E., Blight, K., Sundaramoorthy, S., Takaki, T., et al. (2012). Centralspindlin links the mitotic spindle to the plasma membrane during cytokinesis. Nature 492, 276-279. doi: 10.1038/nature11773

Lindås, A. C., Karlsson, E. A., Lindgren, M. T., Ettema, T. J., and Bernander, R. (2008). A unique cell division machinery in the Archaea. Proc. Natl. Acad. Sci. U.S.A. 105, 18942-18946. doi: 10.1073/pnas.0809467105

Maity, S., Caillat, C., Miguet, N., Sulbaran, G., Effantin, G., Schoehn, G., et al. (2019). VPS4 triggers constriction and cleavage of ESCRT-III helical filaments. Sci Adv. 5:eaau7198. doi: 10.1126/sciadv.aau7198

Malerød, L., and Stenmark, H. (2009). ESCRTing membrane deformation. Cell 136, 15-17. doi: 10.1016/j.cell.2008.12.029

Mandal, T., Lough, W., Spagnolie, S. E., Audhya, A., and Cui, Q. (2020). Molecular simulation of mechanical properties and membrane activities of the ESCRT-III complexes. Biophys. J. 118, 1333-1343. doi: 10.1016/j.bpj.2020. 01.033

McCullough, J., Clippinger, A. K., Talledge, N., Skowyra, M. L., Saunders, M. G., Naismith, T. V., et al. (2015). Structure and membrane remodeling activity of ESCRT-III helical polymers. Science 350, 1548-1551. doi: 10.1126/science. aad 8305

Menon, M. B., and Gaestel, M. (2015). Sep(t)arate or not - how some cells take septin-independent routes through cytokinesis. J. Cell Sci. 128, 1877-1886. doi: $10.1242 /$ jcs. 164830

Mierzwa, B., and Gerlich, D. W. (2014). Cytokinetic abscission: molecular mechanisms and temporal control. Dev. Cell 31, 525-538. doi: 10.1016/j.devcel. 2014.11.006

Mierzwa, B. E., Chiaruttini, N., Redondo-Morata, L., Moser, von Filseck, J., König, J., et al. (2017). Dynamic subunit turnover in ESCRT-III assemblies is regulated by Vps4 to mediate membrane remodelling during cytokinesis. Nat. Cell Biol. 19, 787-798. doi: 10.1038/ncb3559
Monroe, N., Han, H., Gonciarz, M. D., Eckert, D. M., Karren, M. A., Whitby, F. G., et al. (2014). The oligomeric state of the active Vps4 AAA ATPase. J. Mol. Biol. 426, 510-525. doi: 10.1016/j.jmb.2013.09.043

Monroe, N., Han, H., Shen, P. S., Sundquist, W. I., and Hill, C. P. (2017). Structural basis of protein translocation by the Vps4-Vtal AAA ATPase. eLife 6:e24487. doi: 10.7554/eLife.24487

Monroe, N., and Hill, C. P. (2016). Meiotic clade AAA ATPases: protein polymer disassembly machines. J. Mol. Biol. 428, 1897-1911. doi: 10.1016/j.jmb.2015.11. 004

Morita, E., Sandrin, V., Chung, H. Y., Morham, S. G., Gygi, S. P., Rodesch, C. K., et al. (2007). Human ESCRT and ALIX proteins interact with proteins of the midbody and function in cytokinesis. Embo J. 26, 4215-4227. doi: 10.1038/sj. emboj.760185

Moser von Filseck, J., Barberi, L., Talledge, N., Johnson, I. E., Frost, A., Lenz, M., et al. (2020). Anisotropic ESCRT-III architecture governs helical membrane tube formation. Nat. Commun. 11:1516. doi: 10.1038/s41467-020-15327-4

Mullins, J. M., and Biesele, J. J. (1977). Terminal phase of cytokinesis in D-98s cells. J. Cell Biol. 73, 672-684. doi: 10.1083/jcb.73.3.672

Muzioł, T., Pineda-Molina, E., Ravelli, R. B., Zamborlini, A., Usami, Y., Göttlinger, H., et al. (2006). Structural basis for budding by the ESCRT-III factor CHMP3. Dev. Cell 10, 821-830. doi: 10.1016/j.devcel.2006.03.013

Nguyen, H. C., Talledge, N., McCullough, J., Sharma, A., Moss, F. R. III, Iwasa, J. H., et al. (2020). Membrane constriction and thinning by sequential ESCRTIII polymerization. Nat. Struct. Mol. Biol. 27, 392-399. doi: 10.1038/s41594020-0404-x

Obita, T., Saksena, S., Ghazi-Tabatabai, S., Gill, D. J., Perisic, O., Emr, S. D., et al. (2007). Structural basis for selective recognition of ESCRT-III by the AAA ATPase Vps4. Nature 449, 735-739. doi: 10.1038/nature06171

Olmos, Y., and Carlton, J. G. (2016). The ESCRT machinery: new roles at new holes. Curr. Opin. Cell Biol 38, 1-11. doi: 10.1016/j.ceb.2015.12.001

Pfitzner, A. K., Mercier, V., Jiang, X., Moser, von Filseck, J., Baum, B., et al. (2020). An ESCRT-III polymerization sequence drives membrane deformation and fission. Cell 182, 1140.e18-1155.e18. doi: 10.1016/j.cell.2020.07.021

Renshaw, M. J., Liu, J., Lavoie, B. D., and Wilde, A. (2014). Anillin-dependent organization of septin filaments promotes intercellular bridge elongation and Chmp4B targeting to the abscission site. Open Biol. 4:130190. doi: 10.1098/rsob. 130190

Schiel, J. A., Park, K., Morphew, M. K., Reid, E., Hoenger, A., and Prekeris, R. (2011). Endocytic membrane fusion and buckling-induced microtubule severing mediate cell abscission. J. Cell Sci. 124, 1411-1424. doi: 10.1242/jcs. 081448

Schiel, J. A., and Prekeris, R. (2010). Making the final cut - mechanisms mediating the abscission step of cytokinesis. Sci. World J. 10, 1424-1434. doi: 10.1100/tsw. 2010.129

Schiel, J. A., Simon, G. C., Zaharris, C., Weisz, J., Castle, D., Wu, C. C., et al. (2012). FIP3-endosome-dependent formation of the secondary ingression mediates ESCRT-III recruitment during cytokinesis. Nat. Cell Biol. 14, 1068-1078. doi: $10.1038 /$ ncb2577

Schmidt, O., and Teis, D. (2012). The ESCRT machinery. Curr. Biol. 22, 116-120. doi: 10.1016/j.cub.2012.01.028

Schöneberg, J., Lee, I. H., Iwasa, J. H., and Hurley, J. H. (2017). Reverse-topology membrane scission by the ESCRT proteins. Nat. Rev. Mol. Cell Biol. 18, 5-17. doi: $10.1038 / \mathrm{nrm} .2016 .121$

Scott, A., Chung, H. Y., Gonciarz-Swiatek, M., Hill, G. C., Whitby, F. G., Gaspar, J., et al. (2005). Structural and mechanistic studies of VPS4 proteins. Embo J. 24, 3658-3669. doi: 10.1038/sj.emboj.7600818

Sherman, S., Kirchenbuechler, D., Nachmias, D., Tamir, A., Werner, S., Elbaum, M., et al. (2016). Resolving new ultrastructural features of cytokinetic abscission with soft-X-ray cryo-tomography. Sci Rep. 6:27629. doi: 10.1038/srep27629

Shestakova, A., Curtiss, M., Davies, B. A., Katzmann, D. J., and Babst, M. (2013). The linker region plays a regulatory role in assembly and activity of the Vps4 AAA ATPase. J. Biol. Chem. 288, 26810-26819. doi: 10.1074/jbc.M113.497032

Shestakova, A., Hanono, A., Drosner, S., Curtiss, M., Davies, B. A., Katzmann, D. J., et al. (2010). Assembly of the AAA ATPase Vps4 on ESCRT-III. Mol. Biol. Cell 21, 1059-1071. doi: 10.1091/mbc.e09-07-0572

Skop, A. R., Liu, H., Yates, J. III, Meyer, B. J., and Heald, R. (2004). Dissection of the mammalian midbody proteome reveals conserved cytokinesis mechanisms. Science 305, 61-66. doi: 10.1126/science. 1097931 
Stoten, C. L., and Carlton, J. G. (2018). ESCRT-dependent control of membrane remodelling during cell division. Semin. Cell Dev. Biol. 74, 50-65. doi: 10.1016/ j.semcdb.2017.08.035

Stuchell-Brereton, M. D., Skalicky, J. J., Kieffer, C., Karren, M. A., and Ghaffarian, S. (2007). Sundquist W.I. ESCRT-III recognition by VPS4 ATPases. Nature 449, 740-744. doi: 10.1038 /nature 06172

Su, M., Guo, E. Z., Ding, X., Li, Y., Tarrasch, J. T., Brooks, C. L. III, et al. (2017). Mechanism of Vps4 hexamer function revealed by cryo-EM. Sci. Adv. 3:e1700325. doi: 10.1126/sciadv.1700325

Takahashi, N., Hatakeyama, H., Okado, H., Miwa, A., Kishimoto, T., Kojima, T., et al. (2004). Sequential exocytosis of insulin granules is associated with redistribution of SNAP25. J. Cell Biol. 165, 255-262. doi: 10.1083/jcb. 200312033

Tang, S., Buchkovich, N. J., Henne, W. M., Banjade, S., Kim, Y. J., and Emr, S. D. (2016). ESCRT-III activation by parallel action of ESCRT-I/II and ESCRT0/Bro1 during MVB biogenesis. eLife 5:e15507. doi: 10.7554/eLife.15507

Tang, S., Henne, W. M., Borbat, P. P., Buchkovich, N. J., Freed, J. H., Mao, Y., et al. (2015). Structural basis for activation, assembly and membrane binding of ESCRT-III Snf7 filaments. eLife 4:e12548. doi: 10.7554/eLife.12548

Teis, D., Saksena, S., and Emr, S. D. (2008). Ordered assembly of the ESCRT-III complex on endosomes is required to sequester cargo during MVB formation. Dev. Cell 15, 578-589. doi: 10.1016/j.devcel.2008.08.013

Thoresen, S. B., Campsteijn, C., Vietri, M., Schink, K. O., Liestøl, K., Andersen, J. S., et al. (2014). ANCHR mediates Aurora-B-dependent abscission checkpoint control through retention of VPS4. Nat. Cell Biol. 16, 550-560. doi: 10.1038/ ncb2959

Vietri, M., Schink, K. O., Campsteijn, C., Wegner, C. S., Schultz, S. W., Christ, L., et al. (2015). Spastin and ESCRT-III coordinate mitotic spindle disassembly and nuclear envelope sealing. Nature 522, 231-235. doi: 10.1038/nature14408

Wheatley, S. P., Hinchcliffe, E. H., Glotzer, M., Hyman, A. A., Sluder, G., and Wang, Y. L. (1997). CDK1 inactivation regulates anaphase spindle dynamics and cytokinesis in vivo. J. Cell Biol. 138, 385-393. doi: 10.1083/jcb.138. 2.385
Wheatley, S. P., and Wang, Y. (1996). Midzone microtubule bundles are continuously required for cytokinesis in cultured epithelial cells. J. Cell Biol. 135, 981-989. doi: $10.1083 /$ jcb.135.4.981

Wollert, T., Wunder, C., Lippincott-Schwartz, J., and Hurley, J. H. (2009). Membrane scission by the ESCRT-III complex. Nature 458, 172-177. doi: 10. 1038/nature07836

Yang, B., Stjepanovic, G., Shen, Q., Martin, A., and Hurley, J. H. (2015). Vps4 disassembles an ESCRT-III filament by global unfolding and processive translocation. Nat. Struct. Mol. Biol. 22, 492-498. doi: 10.1038/nsmb.3015

Yang, D., Rismanchi, N., Renvoisé, B., Lippincott-Schwartz, J., Blackstone, C., and Hurley, J. H. (2008). Structural basis for midbody targeting of spastin by the ESCRT-III protein CHMP1B. Nat. Struct. Mol. Biol. 15, 1278-1286. doi: $10.1038 / \mathrm{nsmb} .1512$

Yeo, S. C., Xu, L., Ren, J., Boulton, V. J., Wagle, M. D., Liu, C., et al. (2003). Vps20p and Vtalp interact with Vps4p and function in multivesicular body sorting and endosomal transport in Saccharomyces cerevisiae. J. Cell Sci. 116, 3957-3970. doi: $10.1242 /$ jcs. 00751

Zhu, L., Jorgensen, J. R., Li, M., Chuang, Y. S., and Emr, S. D. (2017). ESCRTs function directly on the lysosome membrane to downregulate ubiquitinated lysosomal membrane proteins. eLife 6:e26403. doi: 10.7554/eLife. 26403

Conflict of Interest: The authors declare that the research was conducted in the absence of any commercial or financial relationships that could be construed as a potential conflict of interest.

Copyright (c) 2020 Horváth and Müller-Reichert. This is an open-access article distributed under the terms of the Creative Commons Attribution License (CC BY). The use, distribution or reproduction in other forums is permitted, provided the original author(s) and the copyright owner(s) are credited and that the original publication in this journal is cited, in accordance with accepted academic practice. No use, distribution or reproduction is permitted which does not comply with these terms. 